\title{
An extremely rare case of choroid plexus carcinoma in third ventricle of an infant - Case report and review of literature
}

\section{Amin Tavallaii ( $\square$ tavallaeia@mums.ac.ir)}

Neurosurgery department, Akbar children's hospital, Mashhad University of Medical Sciences, Mashhad, Iran https://orcid.org/0000-0003-2486-2919

\section{Ehsan Keykhosravi}

Neurosurgery department, Akbar children's hospital, Mashhad University of Medical Sciences, Mashhad, Iran

\section{Hamid Rezaee}

Neurosurgery department, Mashhad University of Medical Sciences, Mashhad, Iran

\section{Mohsen Khamoushi}

Neurosurgery department, Mashhad University of Medical Sciences, Mashhad, Iran

Keywords: Choroid plexus carcinoma, Third ventricle, infant

Posted Date: April 22nd, 2020

DOI: https://doi.org/10.21203/rs.3.rs-23818/v1

License: (c) (i) This work is licensed under a Creative Commons Attribution 4.0 International License.

Read Full License

Version of Record: A version of this preprint was published at Interdisciplinary Neurosurgery on December 1st, 2020. See the published version at https://doi.org/10.1016/j.inat.2020.100873. 


\section{Abstract}

Background: Choroid plexus tumors are rare intraventricular tumors. Most of these tumors are benign choroid plexus papillomas. Choroid plexus carcinoma is the most malignant choroid plexus tumor and comprise a small percentage of these tumors. Most common location of these tumors are lateral ventricle and fourth ventricle in pediatric and adult patients respectively. Rare locations such as third ventricle are reported in the literature with 55 reports of choroid plexus papilloma and just 3 cases of carcinoma located in third ventricle.

Case description: we present an extremely rare case of choroid plexus carcinoma of third ventricle in a 9 months old boy which was resected successfully through transcortical-transforaminal approach along with a review of literature available around different aspects of these tumors.

Conclusion: Choroid plexus carcinomas even in rare locations such as third ventricle can be effectively resected through transcortical-transforaminal approach, although post-operative subdural effusion can be a potential complication.

\section{Established Facts And Novel Insights}

\section{Established Facts}

- Choroid plexus tumors of pediatric population are more common in lateral ventricles.

- Choroid plexus papillomas consist the majority of choroid plexus tumors and choroid plexus carcinomas account for a small percentage of these tumors.

- Pre-operative CSF shunting is a well-known strategy in cases of neurological deterioration although the optimal management of hydrocephalus in these patients is a matter of debate.

\section{Novel Insights}

- Choroid plexus tumors of third ventricle are rare among both pediatric and adult patients with only 58 cases reported in the literature.

- Choroid plexus carcinoma od third ventricle is extremely rare and there are only 3 reports in the literature up to now.

- Transcortical transforaminal approach can be safe and effective in resection of even highly vascular lesions of third ventricle such as choroid plexus tumors, although post-operative CSF hygroma is a drawback.

- Pre-operative CSF shunting in this case led to overdrainage related complications which highlights the controversy about optimal management of hydrocephalus in these patients in emergent or elective situations.

\section{Background}


Third ventricular tumors are uncommon and account for about $0.6-0.9 \%$ of all brain tumors (1). Choroid plexus tumors (CPTs) are rare CNS tumors and comprise $0.5 \%-0.6 \%$ of intracranial neoplasms in all ages $(2,3)$. These tumors are classified as WHO grade I choroid plexus papilloma (CPP), WHO grade II atypical choroid plexus papilloma (aCPP) and WHO grade III choroid plexus carcinoma (CPC) (4). Ten percent of CPTs are seen in children younger than 5 years(5). Its common location is in the lateral ventricle and fourth ventricle in children and adults respectively $(6-8)$. The third ventricle is an uncommon location for CPTs beside other rare locations such as cerebellopontine angle or brain parenchyma (9-11). aCPP and CPC together comprise about 25 percent of all CPTs(12). To our knowledge there are 55 cases of CPP and just 3 cases of CPC (13-15) reported in third ventricle in the literature to date and this is the $4^{\text {th }}$ report of an extremely rare third ventricle choroid plexus carcinoma till now. So, we present a case of CPC in anterior third ventricle which was successfully excised through a transcortical-transforaminal approach.

\section{Case Report}

\section{History and physical examination:}

A 9 months old male infant was referred to our institute with symptoms of rise in intracranial pressure (ICP) such as macrocephaly (head circumference: $47 \mathrm{~cm}-90^{\text {th }}$ percentile) and sunset eyes since a couple of weeks before admission. Upon detailed examination, patient was conscious but lethargic and without crying response to stimulus. Bulging and tension of anterior fontanelle was clearly evident. The infant's muscle tones were significantly diminished without noticeable paresis. Upon funduscopic examination, bilateral papilledema was encountered.

\section{Imaging findings:}

In non-contrast computed tomographic (CT) scanning, a large lobulated relatively hyperdense mass lesion was evident in anterior third ventricle causing significant hydrocephalus (Figure 1). Following MRI evaluation, the lesion appeared as isointense lobulated mass relative to white matter on both noncontrast T1 and T2 with significant homogenous bright enhancement on contrast enhanced T1 images. The lesion diameters measured approximately $26.5 * 33.2 * 28.4 \mathrm{~mm}$ and was located within anterior two third of third ventricle causing significant ventriculomegaly and periventricular edema (Figure 2).

\section{Management and surgical technique:}

Due to progressive drowsiness and unresponsiveness of patient during course of admission and suboptimal situation for emergent tumor resection, he was initially treated with an emergent ventriculoperitoneal shunting (VPS) procedure which led to significant improvement in patient symptoms. As a result of higher infection rate of external ventricular drains, we preferred a shunt over ventriculostomy. Two days later, the patient undergone an elective total resection of tumor through a right frontal transcortical-transforaminal approach to third ventricle. After general anesthesia, patient was positioned in supine position on a horseshoe head holder and with 20 degrees of head elevation. After administration of local anesthetic, a horseshoe incision was made on right side centered $2 \mathrm{~cm}$ lateral to 
midline and anterior to coronal suture. After a minor craniotomy anterior to coronal suture, dura was opened and reflected medially. Approach to frontal horn of right lateral ventricle was made through superior frontal sulcus and after placement of retractors, a dilated Monroe foramen occupied by a cauliflower friable grayish-red colored tumor was evident. Due to significant bleeding of these tumors, microscopic circumferential dissection, coagulation and disconnection of tumor vascular supply from third ventricle roof was performed initially and then tumor was removed divided into a few large segments without significant bleeding.

\section{Post-operative course:}

Patient was totally alert and without neurological deficit in immediate post-op period and also passed an uneventful post-operative period. The infant was transferred from ICU and discharged from hospital on postoperative day 1 and 3 respectively. Post-operative MR imaging revealed total tumor removal with no residual enhancement, no evidence of injury to fornix, a significant decrease in ventricular size and a small right convexity hygroma (Figure 3 ). The infant was brought for follow-up visit 2 weeks after discharge along with a follow-up CT scan. Despite lack of any signs and symptoms of intracranial hypertension or neurological deficit, significant shunt overdrainage and resultant hygroma was evident in CT scan (Figure 4). So patient was admitted and shunt closure was done at the level of clavicle and after two days of monitoring patient for hydrocephalus, it was completely removed. Patient was discharged totally free of any complaints or symptoms and referred to oncologist for adjuvant chemotherapy. Patient received chemotherapy with Cisplatin, Etoposide, Vincristine regimen and it was well tolerated by patient. Up to now, patient is followed for 8 months and there is no neurological or imaging findings of recurrence or complications.

\section{Pathological findings:}

Histological examination showed a papillary neoplasm with fibrovascular connective tissue covered by multiple layers of cubic to columnar cells with significant hypercellularity. Multiple foci of necrosis and pleomorphism were evident. Conspicuous mitoses were seen and measured Ki67/MIB-1 labeling index was $20 \%$. So, diagnosis of choroid plexus carcinoma (WHO grade 3 ) was reported (Figure 5).

\section{Discussion}

\section{Epidemiology:}

CPTs are rare CNS tumors and account for $0.5 \%-0.6 \%$ of all intracranial neoplasms in all ages $(2,3)$. About $5 \%$ of all CPTs are located in third ventricle(16). According to multiple reports, third ventricle CPP comprise a very rare entity $(11,17,18) .14 \%$ of choroid plexus tumors occur during infancy although there are reports of third ventricle choroid plexus papilloma during $5^{\text {th }}$ decade of life $(19,20)$. In majority of reports there is no reported sex predilection in CPTs $(21,22)$. CPCs are almost 4 fold more common in children than adults(12). In literature there are 55 cases of reported CPPs and just three cases of CPC located in third ventricle which elicits extreme rarity of third ventricle CPC. 


\section{Clinical features:}

According to anatomic specifications of third ventricle, CPTs in this location tend to be symptomatic earlier in life than tumors located in other common locations(23). Common presentation in pediatric population is hydrocephalus manifested as macrocephaly, splaying of cranial sutures, fontanel widening/bulging and forced downward gaze, also known as sunset eyes. Older patients suffer from headache, nausea, vomiting and visual disturbances (24). These tumors can infrequently manifest as bobbing head doll syndrome or endocrine abnormalities $(24,25)$. In our case, ICP rising manifestations such as sunset eyes and sutural splaying was dominant regarding patient's age.

\section{Imaging characteristics:}

In CT and MR imaging, CPTs present as well-defined large lobulated masses. They appear as hyperdense structures in CT images as a result of micro-hemorrhages and micro-calcifications(26). On MR imaging, tumor signal usually seems to be isointense on $\mathrm{T} 1$ and isointense to moderately hyperintense on $\mathrm{T} 2$ sequences. Due to high vascularity of structures derived from choroid plexus, these tumors enhance brightly and homogenously after administration of contrast agent on both CT and MRI. Calcifications are rare in children but may be seen in $14-25 \%$ of cases in all ages $(25,27)$. There is no specific imaging criteria for CPCs, but parenchymal invasion or heterogeneous enhancement as a result of necrotic areas, calcifications or micro-hemorrhages may be a clue(28). As can be seen, there was no such imaging characteristics of carcinomas in our case which emphasize on the fact that CPCs can't be diagnosed solely on radiological grounds. CPTs are often accompanied by significant hydrocephalus.

Pathophysiology of hydrocephalus can be related to CSF overproduction, obstruction of CSF pathways, hemorrhage from tumor leading to arachnoid villi dysfunction and high CSF protein content $(7,11,25)$. Despite all these imaging specifications, diagnosis may be challenging in uncommon locations.

\section{Histopathology:}

Microscopically, CPPs are composed of well-structured fibrovascular papillary formations lined by single layer of columnar or cuboidal epithelium without malignant features. In contrast, CPCs are recognized with presence of at least four of five malignant features such as increased cellularity, high mitotic activity (more than 5 in $10 \mathrm{HPF}$ ), multiple areas of necrosis, highly pleomorphic nuclei and blurring of papillary architecture(4). Occasionally, CPTs show one or few of aforementioned malignant parameters but not enough to classify them as CPC. So, aCPP is recognized as an intermediate entity regarding mitotic activity since 2007 WHO classification. Clear diagnostic criteria have not been established but high mitotic figures (more than 2 in $10 \mathrm{HPF}$ ) without other malignant features can lead to diagnosis of aCPP(12). There is a direct relationship between $\mathrm{Ki}-67 / \mathrm{MIB}-1$ staining and tumor grade. Mean values of MIB-1 index in CPP, aCPP and CPC are reported as 1.3-4.5, 5.8-9.1 and 13.4-20.3 percent respectively (29-31). In histological examination of tumor specimen in our case, diffuse blurring of papillary structures, increased cellularity, multiple areas of necrosis and significant pleomorphism was evident leading to diagnosis of CPC. Measured MIB-1 index was $20 \%$ which is also in favor of CPC. 


\section{Management:}

Surgical resection is first line treatment in all CPTs. Because of small diameters and complex neuroanatomy of third ventricle, resection of tumors in this area are challenging and highly demands expertise(32). Due to high vascularity of these tumors significant blood loss during resection should be anticipated and effectively managed specially in pediatric population $(7,11,21,25)$. Blood loss can be limited by initial finding and securing of arterial feeders which are branches of adjacent choroidal arteries and subsequent coagulation and en-bloc or piecemeal removal of tumor bulk $(7,10,24)$. There are some reports of pre-operative embolization of feeder artery, however this approach is challenging and have potential risks of vessel injury or stroke $(25,32,33)$. Neoadjuvant chemotherapy can be considered as an alternative approach which reduces tumor size and vascularity and facilitates total resection (34).

Optimal management of hydrocephalus in these patients is a matter of debate. Majority of reports suggest emergent ventriculoperitoneal shunting (VPS) procedure in cases of neurological deterioration and definite resection of tumor a few days later after patient stabilization, when facilities for emergent total tumor resection is not accessible. In patients with stable neurological situation, semi-urgent external ventricular drainage (EVD) placement and tumor resection in one session will be feasible. In these circumstances, EVD tapering and removal or change to VPS should be considered as soon as possible given the high risk of meningitis with EVD in place $(11,35)$. Pre-operative endoscopic third ventriculostomy (ETV) is another option in patients with non-communicating hydrocephalus with different reported success rates(7). In our case, patient showed significant neurological deterioration as drowsiness and lack of response to stimuli upon admission and severe hydrocephalus on imaging. So, because facilities for emergent resection of tumor were not available, we decided to emergently place a VPS which resulted in dramatic clinical response.

Although we resected tumor through transcortical-transforaminal approach, there are different surgical approaches for different locations of CPTs. Specifically for third ventricle CPTs, transcallosal, transcortical-transforaminal and endoscopic approaches can be used for resection of tumors located in anterior third ventricle and infratentorial-supracerebellar, occipital-transtentorial and transcallosal approaches are among the described approaches to posterior third ventricle tumors $(10,11,36)$. The choice of surgical approach varies based on location, anatomy, size, and blood supply of tumor. The transcortical-transforaminal approach is ideal for patients with larger tumors and larger ventricles as in our case. Most frequent complication of this approach is seizure and subdural collection, the latter occurred in our case (37). Although the aim of surgery is gross total resection, it may be not possible as a result of significant bleeding (especially in children) or invasion to critical structures. In former situation, reoperation at a later time is suggested but adjuvant therapy can be used in later $(11,35)$.

Neuroendoscopic biopsy followed by chemoradiotherapy is the best treatment option in cases where the tumor is not resectable (38).

Role of adjuvant therapies in management of CPTs is controversial. As a consensus, completely removed CPP can be followed without any adjuvant therapy. There are some reports of radiotherapy or 
radiosurgery in CPTs but they all suggest that these modalities be reserved for patients with unresectable residual tumor or aggressive subtypes $(35,39,40)$. Chemotherapy is suggested in cases of higher grade tumors or recurrences, although it showed mixed results. The most debate in this regard is about role of adjuvant therapy in aCPPs which is relatively newer entity with few cases reported in literature $(41,42)$. Role of adjuvant therapy in CPC is more obvious with some reports of significant increase in overall survival following adjuvant chemoradiotherapy or chemotherapy alone $(28,42-44)$.

\section{Outcome:}

Main prognostic factors in CPTs are extent of resection and tumor grade. Best outcome is expected in totally removed CPPs with10 year survival of about $100 \%$ in different reports $(6,24,45)$. Whereas, 5 -year survival rate of CPC patients are approximately $58 \%$ and $20 \%$ after complete or partial resection respectively(28). Natural history and outcome of aCPPs fall somewhere in between, but is not well recognized and needs to be elucidated.

\section{Conclusion}

As we presented, a highly malignant tumor such as CPC in a surgically challenging location such as third ventricle can be managed effectively and safely through transcortical-transforaminal approach. A wellknown drawback of this approach is post-operative subdural effusion that can be managed on an individualized basis.

\section{Declarations}

\section{Statement of Ethics.}

Parents of presented patient have given their written informed consent to publish their case, although all information revealing subject's identity is avoided in this manuscript.

\section{Declarations of interest:}

The authors declare that they have no known competing financial interests or personal relationships that could have appeared to influence the work reported in this paper.

\section{Funding Sources:}

This research did not receive any specific grant from funding agencies in the public, commercial, or notfor-profit sectors.

\section{Author Contributions:}

Amin Tavallaii: Conception and design, Critical revising, Final approval

Ehsan Keykhosravi: Data acquisition, Drafting, Final approval 
Hamid Rezaee: Data acquisition, Drafting, Final approval

Mohsen Khamoushi: Data acquisition, Drafting, Final approval

\section{References}

1. Chibbaro S, Di Rocco F, Makiese O, Reiss A, Poczos P, Mirone G, et al. Neuroendoscopic management of posterior third ventricle and pineal region tumors: technique, limitation, and possible complication avoidance. Neurosurgical review. 2012;35(3):331-38; discussion 8-40.

2. Felix I, Phudhichareonrat S, Halliday WC, Becker LE. Choroid plexus tumors in children: immunohistochemical and scanning-electron-microscopic features. Pediatric neuroscience. 1987;13(5):263-9.

3. Gupta N. Choroid plexus tumors in children. Neurosurgery clinics of North America. 2003;14(4):62131.

4. Chhabda S, Carney O, D'Arco F, Jacques TS, Mankad K. The 2016 World Health Organization Classification of tumours of the Central Nervous System: what the paediatric neuroradiologist needs to know. Quantitative imaging in medicine and surgery. 2016;6(5):486-9.

5. Suh DY, Mapstone T. Pediatric supratentorial intraventricular tumors. Neurosurgical focus. 2001;10(6):E4.

6. Bettegowda C, Adogwa O, Mehta V, Chaichana KL, Weingart J, Carson BS, et al. Treatment of choroid plexus tumors: a 20-year single institutional experience. Journal of neurosurgery Pediatrics. 2012;10(5):398-405.

7. Jaiswal AK, Jaiswal S, Sahu RN, Das KB, Jain VK, Behari S. Choroid plexus papilloma in children: Diagnostic and surgical considerations. Journal of pediatric neurosciences. 2009;4(1):10-6.

8. Ogiwara H, Dipatri AJ, Jr., Alden TD, Bowman RM, Tomita T. Choroid plexus tumors in pediatric patients. British journal of neurosurgery. 2012;26(1):32-7.

9. Kumar R, Achari G, Benerji D, Jain VK, Chhabra DK. Choroid plexus papillomas of the cerebellopontine angle. Neurology India. 2002;50(3):352-8.

10. Mishra A, Ojha BK, Chandra A, Singh SK, Chandra N, Srivastava C. Choroid plexus papilloma of posterior third ventricle: A case report and review of literature. Asian journal of neurosurgery. 2014;9(4):238.

11. Pawar SJ, Sharma RR, Mahapatra AK, Lad SD, Musa MM. Choroid plexus papilloma of the posterior third ventricle during infancy \& childhood: report of two cases with management morbidities. Neurology India. 2003;51(3):379-82.

12. Louis DN, Ohgaki H, Wiestler OD, Cavenee WK, Burger PC, Jouvet A, et al. The 2007 WHO classification of tumours of the central nervous system. Acta neuropathologica. 2007;114(2):97-109.

13. Zhou WJ, Wang X, Peng JY, Ma SC, Zhang DN, Guan XD, et al. Clinical Features and Prognostic Risk Factors of Choroid Plexus Tumors in Children. Chinese medical journal. 2018;131(24):2938-46. 
14. Sato K, Hayashi M, Kubota T, Kawano H. [A case of large malignant choroid plexus papilloma in the third ventricle-immunohistochemical and ultrastructural studies]. No to shinkei = Brain and nerve. 1989;41(10):973-8.

15. Broad RW, Allen PB. Third ventricle choroid plexus carcinoma. The Canadian journal of neurological sciences Le journal canadien des sciences neurologiques. 1984;11(4):461-5.

16. Levy ML, Goldfarb A, Hyder DJ, Gonzales-Gomez I, Nelson M, Gilles FH, et al. Choroid plexus tumors in children: significance of stromal invasion. Neurosurgery. 2001;48(2):303-9.

17. Razzaq AA, Chishti KN. Giant choroid plexus papilloma of the third ventricle. JPMA The Journal of the Pakistan Medical Association. 2003;53(11):573-5.

18. Schijman E, Monges J, Raimondi AJ, Tomita T. Choroid plexus papillomas of the III ventricle in childhood. Their diagnosis and surgical management. Child's nervous system : ChNS : official journal of the International Society for Pediatric Neurosurgery. 1990;6(6):331-4.

19. Nakano I, Kondo A, Iwasaki K. Choroid plexus papilloma in the posterior third ventricle: case report. Neurosurgery. 1997;40(6):1279-82.

20. Tomasello F, Albanese V, Bernini FP, Picozzi P. Choroid plexus papilloma of the third ventricle. Surgical neurology. 1981;16(1):69-71.

21. Safaee M, Clark AJ, Bloch O, Oh MC, Singh A, Auguste KI, et al. Surgical outcomes in choroid plexus papillomas: an institutional experience. Journal of neuro-oncology. 2013;113(1):117-25.

22. Shin JH, Lee HK, Jeong AK, Park SH, Choi CG, Suh DC. Choroid plexus papilloma in the posterior cranial fossa: MR, CT, and angiographic findings. Clinical imaging. 2001;25(3):154-62.

23. Tomita T, McLone DG, Flannery AM. Choroid plexus papillomas of neonates, infants and children. Pediatric neuroscience. 1988;14(1):23-30.

24. Menon G, Nair SN, Baldawa SS, Rao RB, Krishnakumar KP, Gopalakrishnan CV. Choroid plexus tumors: an institutional series of 25 patients. Neurology India. 2010;58(3):429-35.

25. Koeller KK, Sandberg GD. From the archives of the AFIP. Cerebral intraventricular neoplasms: radiologic-pathologic correlation. Radiographics : a review publication of the Radiological Society of North America, Inc. 2002;22(6):1473-505.

26. Coates TL, Hinshaw DB, Jr., Peckman N, Thompson JR, Hasso AN, Holshouser BA, et al. Pediatric choroid plexus neoplasms: MR, CT, and pathologic correlation. Radiology. 1989;173(1):81-8.

27. McEvoy AW, Harding BN, Phipps KP, Ellison DW, Elsmore AJ, Thompson D, et al. Management of choroid plexus tumours in children: 20 years experience at a single neurosurgical centre. Pediatric neurosurgery. 2000;32(4):192-9.

28. Sun MZ, Oh MC, Ivan ME, Kaur G, Safaee M, Kim JM, et al. Current management of choroid plexus carcinomas. Neurosurgical review. 2014;37(2):179-92; discussion 92.

29. Wrede B, Hasselblatt M, Peters O, Thall PF, Kutluk T, Moghrabi A, et al. Atypical choroid plexus papilloma: clinical experience in the CPT-SIOP-2000 study. Journal of neuro-oncology. 2009;95(3):383-92. 
30. Carlotti CG, Jr., Salhia B, Weitzman S, Greenberg M, Dirks PB, Mason W, et al. Evaluation of proliferative index and cell cycle protein expression in choroid plexus tumors in children. Acta neuropathologica. 2002;103(1):1-10.

31. Vajtai I, Varga Z, Aguzzi A. MIB-1 immunoreactivity reveals different labelling in low-grade and in malignant epithelial neoplasms of the choroid plexus. Histopathology. 1996;29(2):147-51.

32. Do HM, Marx WF, Khanam H, Jensen ME. Choroid plexus papilloma of the third ventricle: angiography, preoperative embolization, and histology. Neuroradiology. 2001;43(6):503-6.

33. Trivelato FP, Manzato LB, Rezende MT, Barroso PM, Faleiro RM, Ulhoa AC. Preoperative embolization of choroid plexus papilloma with Onyx via the anterior choroidal artery: technical note. Child's nervous system : ChNS : official journal of the International Society for Pediatric Neurosurgery. 2012;28(11):1955-8.

34. Koh EJ, Wang KC, Phi JH, Lee JY, Choi JW, Park SH, et al. Clinical outcome of pediatric choroid plexus tumors: retrospective analysis from a single institute. Childs Nerv Syst. 2014;30(2):217-25.

35. Talacchi A, De Micheli E, Lombardo C, Turazzi S, Bricolo A. Choroid plexus papilloma of the cerebellopontine angle: a twelve patient series. Surgical neurology. 1999;51(6):621-9.

36. Sasani M, Solmaz B, Oktenoglu T, Ozer AF. An unusual location for a choroid plexus papilloma: the pineal region. Child's nervous system : ChNS : official journal of the International Society for Pediatric Neurosurgery. 2014;30(7):1307-11.

37. Ellenbogen RG. Transcortical surgery for lateral ventricular tumors. Neurosurgical focus. 2001;10(6):E2.

38. Oppido PA, Fiorindi A, Benvenuti L, Cattani F, Cipri S, Gangemi M, et al. Neuroendoscopic biopsy of ventricular tumors: a multicentric experience. Neurosurgical focus. 2011;30(4):E2.

39. Duke BJ, Kindt GW, Breeze RE. Pineal region choroid plexus papilloma treated with stereotactic radiosurgery: a case study. Computer aided surgery : official journal of the International Society for Computer Aided Surgery. 1997;2(2):135-8.

40. Kim IY, Niranjan A, Kondziolka D, Flickinger JC, Lunsford LD. Gamma knife radiosurgery for treatment resistant choroid plexus papillomas. Journal of neuro-oncology. 2008;90(1):105-10.

41. Kamar FG, Kairouz VF, Nasser SM, Faddoul SG, Saikali IC. Atypical choroid plexus papilloma treated with single agent bevacizumab. Rare Tumors. 2014;6(1):4687.

42. Passariello A, Tufano M, Spennato P, Quaglietta L, Verrico A, Migliorati R, et al. The role of chemotherapy and surgical removal in the treatment of Choroid Plexus carcinomas and atypical papillomas. Childs Nerv Syst. 2015;31(7):1079-88.

43. Sun MZ, Ivan ME, Oh MC, Delance AR, Clark AJ, Safaee M, et al. Effects of adjuvant chemotherapy and radiation on overall survival in children with choroid plexus carcinoma. J Neurooncol. 2014;120(2):353-60.

44. Lafay-Cousin L, Mabbott DJ, Halliday W, Taylor MD, Tabori U, Kamaly-AsI ID, et al. Use of ifosfamide, carboplatin, and etoposide chemotherapy in choroid plexus carcinoma. J Neurosurg Pediatr. 2010;5(6):615-21.

Page 10/14 
45. McGirr SJ, Ebersold MJ, Scheithauer BW, Quast LM, Shaw EG. Choroid plexus papillomas: long-term follow-up results in a surgically treated series. Journal of neurosurgery. 1988;69(6):843-9.

\section{Figures}
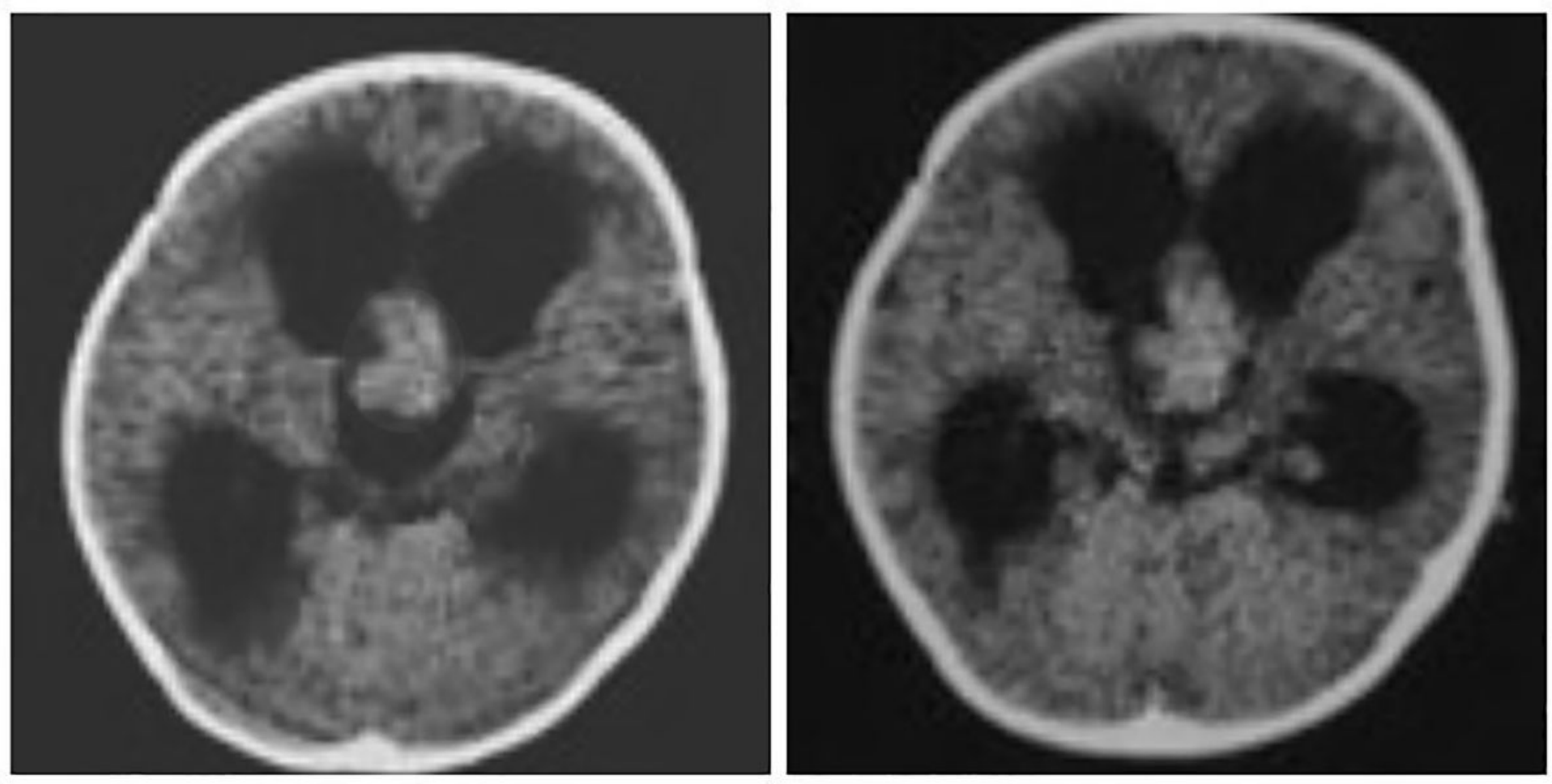

\section{Figure 1}

Pre-operative non-contrast brain CT scan of the infant showing a lobulated hyperdense lesion within third ventricle along with significant hydrocephalus. 


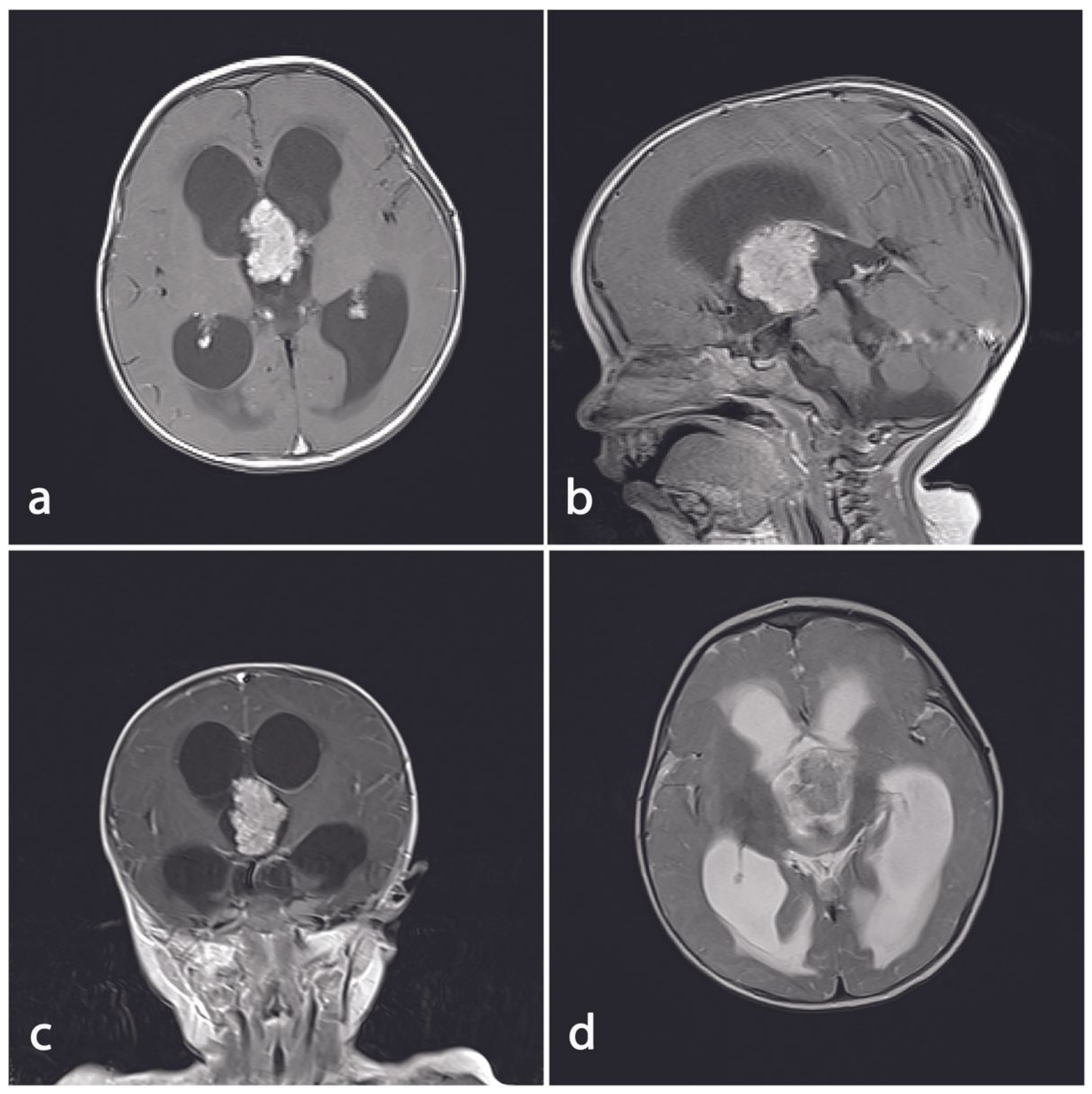

Figure 2

Pre-operative contrast enhanced axial (A), sagittal (B) and coronal (C) brain MR imaging of infant showing lobulated homogenous brightly enhanced lesion within third ventricle. Axial T2 imaging (D) shows lobulated mass with isointense signal relative to white matter and significant periventricular edema. 


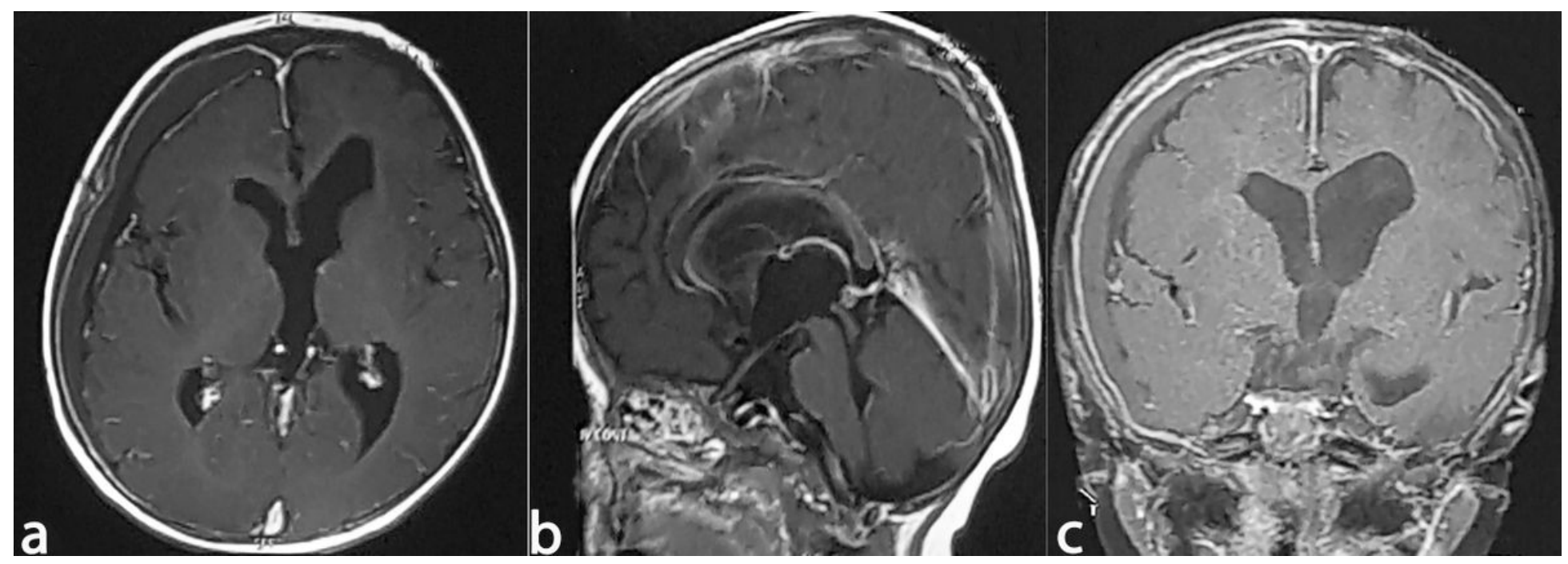

Figure 3

Post-operative contrast enhanced axial (A), sagittal (B) and coronal (C) brain MR imaging of patient showing total tumor removal without any residual enhancement and a small right convexity hygroma.
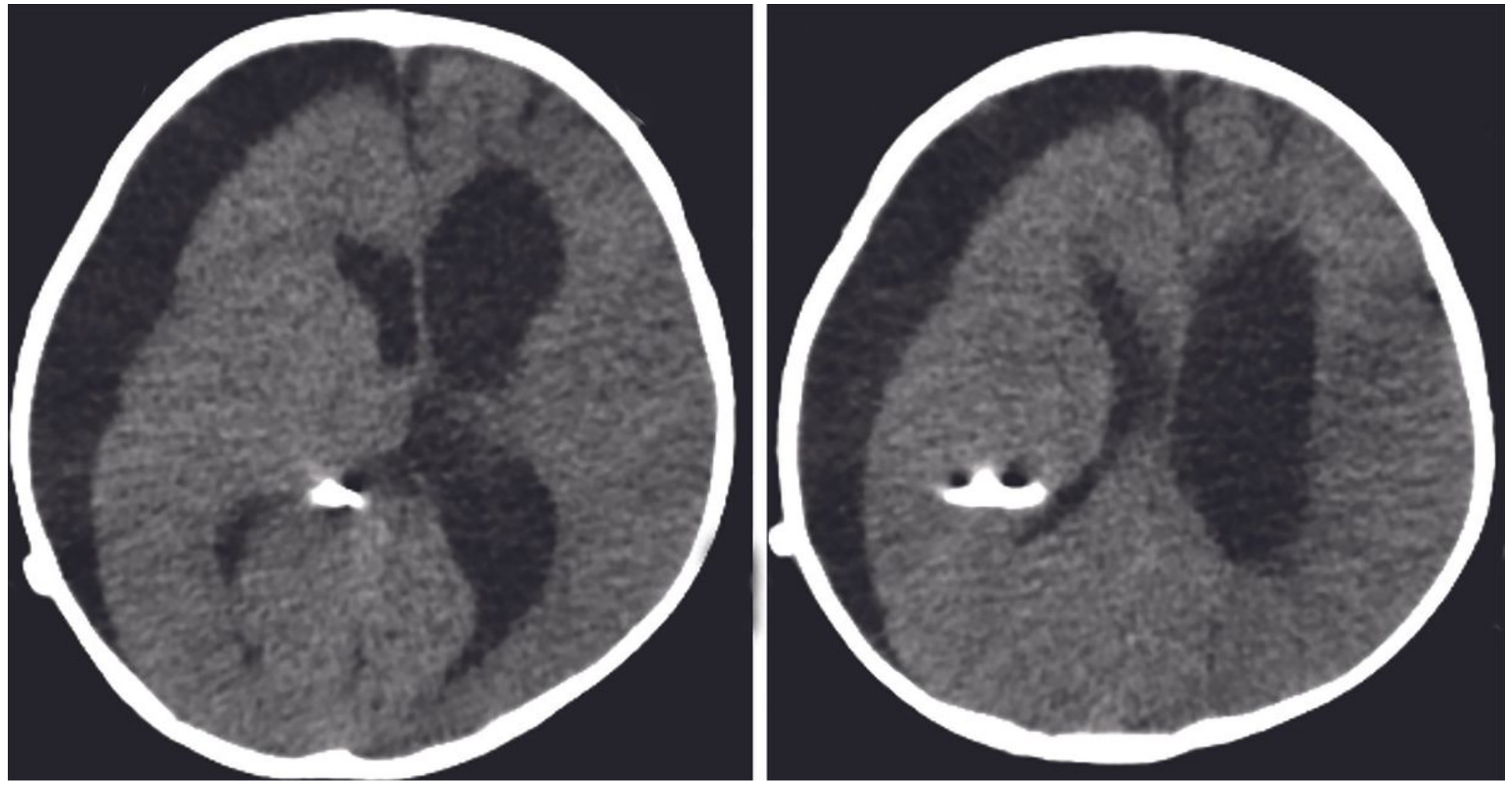

Figure 4

Follow-up brain CT scan of patient 2 weeks after discharge showing significant shunt overdrainage and marked right convexity hygroma. 

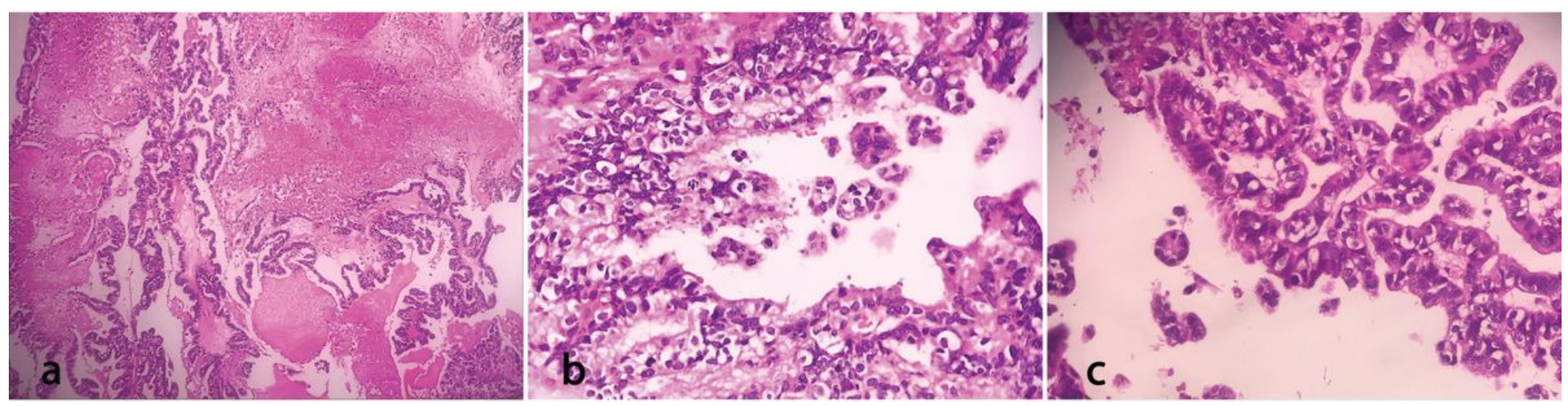

\section{Figure 5}

Histological examination of resected tumor showing focal necrosis (A), hypercellularity and pleomorphism (B) and increased mitosis (C) leading to diagnosis of choroid plexus carcinoma (Hematoxylin-Eosin staining). 